\title{
How Well Does the Patient-Centered Outcomes Research Institute Fund Primary Care and Comparative Effectiveness Research?
}

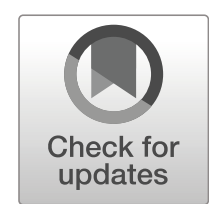

\author{
Andrew Balster, BS ${ }^{7}$, Stephany Mazur, MD², Andrew Bazemore, MD MPH' ${ }^{3}$, and Daniel J. Merenstein, \\ $M D^{4}$
}

'Georgetown University School of Medicine, Washington, DC, USA; ${ }^{2}$ Department of Radiology, Northwestern University, Evanston, IL, USA; ${ }^{3}$ Robert Graham Center for Policy Studies, Washington, DC, USA; ${ }^{4}$ Department of Family Medicine, Georgetown University Medical Center, Washington, DC, USA.

J Gen Intern Med 34(9):1680-1

DOI: $10.1007 / \mathrm{s} 11606-019-04990-z$

(c) Society of General Internal Medicine 2019

\section{INTRODUCTION}

In 2010, the Patient Protection and Affordable Care Act (ACA) established the Patient-Centered Outcomes Research Institute (PCORI) to fund research, with an emphasis on comparative effectiveness research (CER), with the goal of helping patients make better informed healthcare decisions. ${ }^{1}$ CER is patient-centered research that relies on clinical epidemiology and medical decision making to improve evidence for clinicians and patients. The expectation was to reduce waste and improve healthcare outcomes. ${ }^{1}$ Given that primary care represents over half of all physician office visits, ${ }^{2}$ an important question is how well PCORI's funding mirrors the distribution of where patients receive their care. After the first six rounds (2011-2014) of funding, it was identified that the majority of PCORI research did not have a primary care focus (19-32\%). ${ }^{3}$ Our objective was to evaluate funding from PCORI during 2015-2018 to determine if this has changed, and to determine the type and focus of PCORI-funded research.

\section{METHODS}

PCORI-funded studies have a publicly available project summary containing information such as the subject, design, population, outcome, and likely beneficiaries of the study. This enabled two independent reviewers to record the following information (from funding cycles 7-14): setting of the trial, cost of the trial, if the study was CER, and if a primary care question was being examined, and if primary care patients were enrolled. This information was used to determine the studies relation to primary care. It was agreed a priori to error on the side of assigning a study to primary care if there was any question it could be related to primary care. For example, a study of chronic low back pain in which the principal investigator is a physical therapist (PT), and it appears the patients receive care at PT office, was considered primary care.

Published online April 15, 2019

\section{RESULTS}

Two hundred fifty trials funded by PCORI were reviewed. Overall, 60 (24\%) trials were determined to be related to primary care, while $181(72.4 \%)$ funded trials were determined to not be related to primary care (Table 1 ). Out of the 250 trials, 193 (77.2\%) trials were determined to be comparative effectiveness research, while 57 (22.8\%) were not (Table 1). Of the $1,176,400,428$ dollars distributed by PCORI during 20152018, 356,090,240 (30\%) dollars was distributed to primary care-related studies, while 793,613,553 (68\%) dollars were distributed to non-primary care research (Fig. 1).

\section{DISCUSSION}

The year 2018 witnessed the 40th anniversary of the World Health Organization's declaration of Alma Ata, where primary care was declared "an integral part of [any] country's health system, of which it is the central function and main focus". 4 This declaration specifically emphasized the linkage between patient-centeredness and access to primary care, which has been clearly associated with lower costs, and greater equity. ${ }^{5}$ PCORI was created as one manifestation of a broader wave of interest in CER with the goal of steering healthcare financing and research towards issues of greatest impact upon patients. ${ }^{1}$ Subsequently, it would likely be beneficial for primary care to be strongly represented within biomedical research. Additionally, the legendary Johns Hopkins researcher Barbara Starfield ${ }^{6}$ stated that "it is a fallacy to conclude... that primary care research can be done in anything other than primary care settings." While the appropriate ratio of primary care research

Table 1 Characteristics of PCORI Studies Funding Cycles Seven Through Fourteen $(n=250)$

\begin{tabular}{lll}
\hline \hline & Count & \% \\
\hline Primary care relation & & \\
Yes & 60 & 24 \\
No & 181 & 72.4 \\
Undetermined & 9 & 3.6 \\
CER relation & 193 & 77.2 \\
Yes & 57 & 22.8 \\
No & & \\
\hline
\end{tabular}




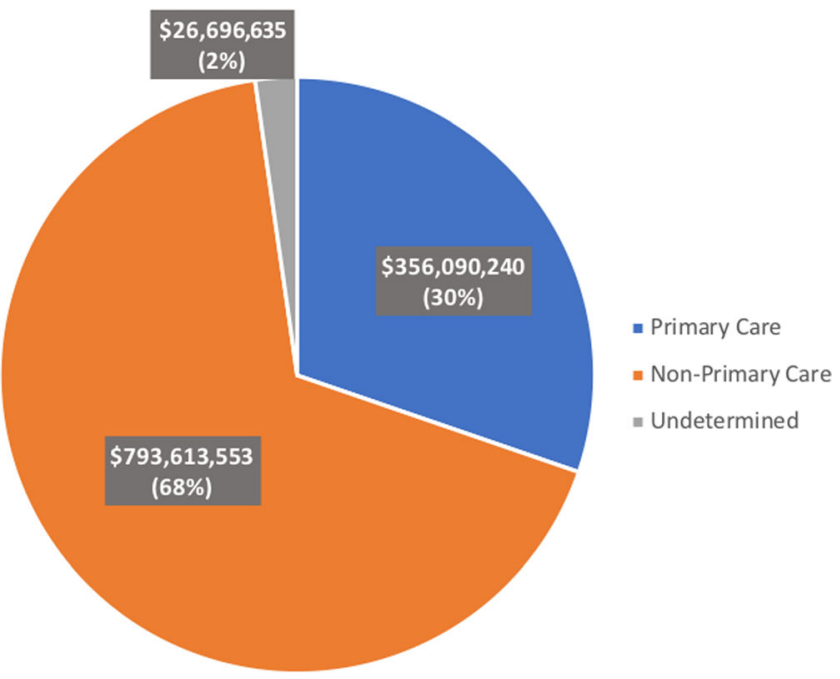

Figure 1 Percentage of funding distributed to primary care- and non-primary care-related research by PCORI during funding cycles seven through fourteen.

to specialty research has yet to be determined, a 2016 study of PCORI's first six funding cycles, ${ }^{3}$ as well as our evaluation of the 7th-14th funding cycles, found relatively low levels of primary care research.

Importantly, this evaluation found that PCORI funded a significant amount of CER $(\sim 80 \%)$. These results come as the institute enters its 10 th, and potentially final year of funding, amidst discussions of funding renewal and its place in the larger ecology of biomedical research. Simultaneously, the Agency for Health Care Research \& Quality (AHRQ), which has been pivotal to primary care research, is facing an existential crisis of its own, leaving primary care without a true research home. A high rate of CER is consistent with PCORI's mission, but funding decisions that prioritize primary care research is also consistent with PCORI's goals. PCORI, through greater attention to questions performed in and relevant to the centerpiece of patient care and delivery, will be better serving its mission and able to persuade not only patient advocates, but also cost-cutting, value-minded policymakers to extend its existence.

Corresponding Author: Daniel J. Merenstein, MD; Department of Family Medicine, Georgetown University Medical Center, Washington, DC, USA (e-mail: djm23@georgetown.edu).

Author Contribution Dr. Merenstein had full access to all the data in the study and takes responsibility for the integrity of the data and the accuracy of the data analysis. The data review was done by DM and Andrew Balster. All authors contributed to the planning of the review and in manuscript preparation.

\section{Compliance with Ethical Standards:}

Conflict of Interest: Dr. Merenstein has previously applied for PCORI grants and has served on PCORI review committees. Additionally, Dr. Merenstein consulted for Bayer, Pharmavite, Reckitt Benckiser and Debevoise; Plimpton for probiotics and has received NIH and AHRQ grants. None of the consulting or grants were related to the subject of this manuscript. All remaining authors declare that they do not have a conflict of interest.

Prior Presentations: Presented at the North American Primary Care Research Group Conference November 2018, Chicago, IL.

\section{REFERENCES}

1. Sox, H. The Patient-Centered Outcomes Research Institute Should Focus On High-Impact Problems That Can Be Solved Quickly. Health Aff. 2012;31(10):2176-2182.

2. White KL, Williams TF, Greenberg BG. The ecology of medical care. N Engl J Med. 1961;265:885-892.

3. Mazur S, Bazemore A, Merenstein D. Characteristics of Early Recipients of Patient-Centered Outcomes Research Institute Funding. Acad Med. 2016;91(4):491-496.

4. Phillips RL, Bazemore AW. Primary Care And Why It Matters For U.S. Health System Reform. Health Aff. 2010;29(5):806-810. https://doi.org/ 10.1377/hlthaff.2010.0020.

5. Starfield B, Shi L, Macinko J. Contribution of Primary Care to Health Systems and Health. Milbank Q. 2005;83(3):457-502. doi:https://doi.org/ 10.1111/j.1468-0009.2005.00409.x.

6. Starfield, B. A Framework for Primary Care Research. J Fam Pract. 1996;42:181-185

Publisher's Note Springer Nature remains neutral with regard to jurisdictional claims in published maps and institutional affiliations. 